\title{
Mulheres na Força Aérea Brasileira: um estudo sobre as primeiras oficiais aviadoras
}

\author{
Marina Miranda Lery Santos \\ Universidade Federal do Rio de Janeiro \\ Maria Lúcia Rocha-Coutinho \\ Universidade Federal do Rio de Janeiro \\ Universidade Salgado de Oliveira
}

\begin{abstract}
Resumo
O artigo apresenta parte dos resultados de um estudo realizado com seis mulheres oficiais formadas na primeira turma do curso de aviação da Aeronáutica. Seu objetivo foi investigar como elas vivenciam a experiência de uma carreira até então vedada a mulheres, como percebem a hierarquia e as relações de poder típicas dessa carreira, e quais os seus projetos profissionais e pessoais para o futuro. Utilizamos entrevistas semiestruturadas, que foram gravadas e transcritas na íntegra; os textos resultantes foram submetidos à análise de discurso. Pudemos constatar nos relatos das entrevistadas a coexistência de padrões contemporâneos e arcaicos; ou seja, ao mesmo tempo em que, de forma pioneira, estão investindo em uma carreira profissional até então aberta apenas aos homens, continuam a sonhar com o casamento e a maternidade nos moldes tradicionais, reforçando a ideia de que a mulher é responsável pelos cuidados com a casa e a criação e educação dos filhos.
\end{abstract}

Palavras-chave: mulheres aviadoras; identidade; força aérea brasileira.

\begin{abstract}
Women in Brazilian Air Force: a study on the first women pilot officers. This article presents part of the results of a study developed with the first Brazilian Air Force women pilots. Its objective was to investigate how they experience the career until then prohibited to women, how they perceive the hierarchy and power relations typical of that professional realm, and what they project for their future. We interviewed six women pilots, whose reports were audio recorded, transcribed, and submitted to discourse analysis. Such analysis pointed to the fact that contemporary and traditional patterns of behavior coexist. At the same time those women invest in a pioneering professional career and search for financial independence, they continue to dream about marriage and motherhood in traditional formats, reinforcing the idea that women are the main responsible for household care and for raising and educating the children.
\end{abstract}

Keywords: women pilots; identity; brazilian air force.

A complexidade do mundo contemporâneo e a intricada rede de interações sociais em que as pessoas se envolvem hoje desencadearam o surgimento de uma grande diversidade de perfis femininos, tornando difícil uma definição da mulher atual; tanto em escala ampla - o perfil da mulher ocidental ou o perfil da mulher brasileira, por exemplo - quanto em escala reduzida - como, por exemplo, a mulher de uma determinada idade, cidade ou profissão. Segundo RochaCoutinho (1994), as mulheres não formam uma unidade centrada no sexo. Apesar de elas viverem realidades sociais bastante desiguais, o que impossibilitaria generalizações nos chamados "estudos de gênero", constatou-se, em pesquisa nacional sobre mulheres brasileiras, realizada em 2001 (Venturi, Recamán, \& Oliveira, 2004), que se pode falar na partilha de "fortes traços de uma identidade comum de gênero" (p. 18).
Embora grande parte das mulheres, pelo menos das classes médias, acredite possuir hoje uma condição melhor na sociedade do que há algumas décadas e tenha expectativas mais positivas com relação ao futuro, ainda se pode perceber em seus discursos traços da presença do papel tradicionalmente atribuído à mulher, do mesmo modo que se pode dizer que a histórica desigualdade social em relação aos homens (Venturi et al., 2004) persiste, ainda que agora de forma talvez mais sutil. No que tange à esfera profissional, é perceptível o aumento da inserção das mulheres de classe média no mercado de trabalho e, como consequência, sua maior independência econômica. Contudo, estudos como o de Araújo e Scalon (2005) e o de Marcondes, Rotenberg, Portela, e Moreno (2003), entre outros, apontam para a permanência de certa assimetria e hierarquia entre os trabalhos desenvolvidos por homens e mulheres, tanto no espaço público - em que os 
homens continuam a receber salários mais elevados que as mulheres e a ocupar cargos de maior poder e prestígio - quanto no privado - em que as mulheres continuam a ser as grandes responsáveis pelos trabalhos domésticos e pelos cuidados e educação dos filhos.

A Força Aérea Brasileira (FAB), neste início de século, abriu suas portas para o ingresso de mulheres na carreira da aviação. Essa abertura teve como estímulo a experiência positiva obtida quando da entrada de mulheres nos quadros femininos, inicialmente criados em 1982, para o exercício de funções burocráticas ou daquelas funções que se enquadrariam no que se poderia considerar "profissões de mulher", , e, posteriormente, no quadro de intendentes ${ }^{3}$, criado no final da década de 1990. Ao mesmo tempo em que esta iniciativa pode ser considerada um avanço - já que, até o momento em que esta pesquisa foi realizada, o Exército e a Marinha não haviam aberto espaço para as mulheres em suas escolas correspondentes -, continua a ser vista com restrições por muitos militares, que questionam a compatibilidade das mulheres, e de suas funções sociais tradicionais, com essa carreira, que tem como uma de suas características a constante ausência do lar por longos períodos de tempo.

Pode-se perceber, nesse posicionamento, a permanência de um pensamento tradicional que se caracteriza, de acordo com Bauman (1999), pela busca da ordem, pela categorização, pela atribuição de rótulos. A pergunta que se levanta aqui é se a identidade das mulheres aviadoras da FAB se vincula ainda à posição tradicional de subordinação, que por muito tempo a mulher ocupou em nossa sociedade, ou se os discursos sobre elas, bem como seus próprios discursos, se alteraram, seguindo hoje novos horizontes nesse meio militar. Diversas são as posições teóricas existentes para se abordar e compreender as identidades. Para embasar nosso estudo, utilizamos as perspectivas que partem do princípio de que elas são socialmente construídas.

Segundo Araújo e Yazbek (2001), o conhecimento, as relações e os indivíduos, na pós-modernidade, são socialmente construídos e, mais especificamente, é o discurso que constrói os indivíduos e seus mundos. Na mesma direção, Fairclough (citado por Vieira, 2005) afirma que "identidade, relações sociais e conhecimento estão textualmente entrelaçados" (p. 212). O discurso é entendido aqui como portador de ideologias que vigoram em um determinado contexto e momento histórico e a construção de identidades é vista como um processo constante de formação e transformação, que varia ao longo do tempo e segundo as mudanças nas representações culturais.

Para Moita Lopes (2003), "todo uso da linguagem envolve alteridade (...) e situacionalidade” (p. 20), sendo impossível, ao pensar o discurso, esquecer os sujeitos envolvidos no contexto de sua produção. Ainda segundo esse autor, que enfatiza o potencial estruturador do discurso, a identidade se define e é construída "nos e pelos discursos que a envolvem ou nos quais ela circula" (p. 20).

Rocha-Coutinho (1994), ao se referir à identidade feminina, afirma que ela tem sido construída a partir de um discurso social que visa atender e se adequar às necessidades e aos mitos de uma sociedade determinada em um momento histórico específico.
Ainda segundo a autora, as identidades dos indivíduos e grupos inserem-se, como construções discursivas, em um projeto globalizante e totalizador que está em consonância com os padrões esperados pela sociedade e pelo momento histórico em que esses indivíduos e grupos estão inscritos.

Nem sempre as identidades foram consideradas fruto de um processo de construção social e, mais especificamente, de um processo discursivo. Por muito tempo se supôs haver uma identidade unificada, coerente e "natural". Assim, atribuía-se às identidades características que eram vistas e aceitas como algo da ordem da essência e, portanto, imutáveis. Acreditamos, contudo, que as identidades se constituem a partir da ideologia dominante, presente no discurso do grupo a que pertencem, ainda que as pessoas tenham a ilusão de que há nelas algo de essencial. Os significados dos discursos a que as pessoas estão expostas refletem e reforçam as visões de mundo desse grupo e, assim, as identidades são construções sociais e não naturais, a nosso ver.

Foi com base na ideologia dominante, expressa e reforçada pelos diferentes discursos sociais, que, na época Moderna, com a separação das esferas pública e privada, se classificou e hierarquizou as diferenças biológicas existentes entre homens e mulheres, que passaram a explicar porque ao homem deveria caber o espaço público do trabalho remunerado e do poder e, à mulher, o espaço privado não remunerado do lar e da reprodução. Com isso, as mulheres foram levadas a ocupar uma posição de subordinação com relação aos homens que vem perdurando durante vários séculos e ainda pode ser sentida, de certa forma, mesmo que em menor grau e de forma menos aparente, nos dias atuais. Esta posição, na época, não deveria sequer ser questionada, uma vez que se justificava e sustentava no argumento de que as diferenças entre os sexos eram biológicas e, como tal, naturais, isto é, da ordem da essência.

É nosso ponto de vista, no entanto, que o discurso desempenha papel importante na diferenciação social entre os sexos e na divisão sexual do trabalho, e os significados e práticas sociais são, não apenas construídos, mas também mantidos e manipulados pelo discurso. Como aponta Rocha-Coutinho (1994), “a linguagem [...] delineia e limita o ‘espaço’ feminino, contribuindo, desta forma, para a construção da subjetividade das mulheres" (p. 55). Assim, ao longo dos anos, algumas características foram atribuídas às mulheres, constituindo uma suposta identidade feminina.

O mundo, porém, vem passando, nas últimas décadas, por intensas transformações que alteraram uma série de visões e conceitos. Para Giddens (2003), por exemplo, o rompimento com a ordem dita tradicional levou a mudanças na concepção de identidade. Nas sociedades tradicionais, as identidades eram definidas e limitadas pelo parentesco, pela localidade e pela própria tradição. Sem os parâmetros da tradição, os indivíduos hoje passaram a conviver com a diversidade e a possibilidade de fazer escolhas, tornando-se mais responsáveis por si e por sua própria vida. Tais transformações provocaram também importantes mudanças nas concepções de classe, gênero, sexualidade, etnia e nacionalidade, bem como nas relações sociais, que acabaram por alterar as visões sobre as identidades, inclusive as de gênero. Assim, segundo Giddens (2002), as 
mulheres atuais, em sua reivindicação por maior autonomia e ingresso na força de trabalho, acabaram por alterar não apenas sua identidade, como também a identidade dos homens e dos grupos com os quais se relacionam.

Com a entrada das mulheres de classe média no mercado de trabalho, elas foram levadas a se entender e se identificar em meio à diversidade de papéis que passaram a ocupar na sociedade, o que acarretou uma série de conflitos para as mulheres dessa camada social. Assim, algumas pesquisas desenvolvidas sobre mulher, trabalho e família, como as incluídas no livro de Venturi et al. (2004), intitulado A mulher brasileira nos espaços público e privado, vêm apontando para o fato de que, ao mesmo tempo em que a maioria das mulheres afirma que, se pudesse escolher, optaria por ter uma profissão e, com isso, gastar menos tempo dedicando-se ao trabalho doméstico e à família, elas também assinalam que, quando os filhos ainda são pequenos, é melhor que o homem trabalhe fora e a mulher fique em casa. Assim, parece que, apesar de as mulheres terem vontade de se envolver mais no exercício de atividades no espaço público, continua a prevalecer a ideia tradicional de que as mulheres sabem cuidar melhor das crianças que os homens.

É nosso ponto de vista que, em qualquer época histórica, são as práticas sociais vigentes em uma sociedade que determinam o tipo de ocupação de homens e mulheres no mercado de trabalho. Segundo Vieira (2005), a entrada da mulher no mercado de trabalho e a ocupação, por parte de algumas mulheres atuais, de cargos até então reservados aos homens desestabiliza e ameaça a hegemonia masculina no espaço público, deixando os homens inseguros e alterando as relações entre homens e mulheres. Muitas vezes, por não conseguirem conviver com a família "descentralizada", os homens abandonam seus lares, o que faz com que as mulheres se tornem as chefes da família (Venturi et al., 2004), ainda que o fato delas ocuparem tal posição não decorra apenas e necessariamente disso.

Para Rocha-Coutinho (2003), “apesar das intensas mudanças sofridas nas últimas décadas, o mundo do trabalho continua a ser definido segundo padrões masculinos" (p. 61). A exclusão explícita das mulheres de alguns cargos e funções foi substituída hoje por formas, na maioria das vezes, veladas de discriminação. Do mesmo modo, a despeito do fato de que as mulheres vêm provando sua capacidade para exercer as mais variadas funções - e isso já é admitido, pelo menos em termos de discurso -, permanece a cobrança sobre elas, e elas próprias continuam a acreditar, que são as principais responsáveis pelos cuidados da casa e, principalmente, dos filhos. Assim, como assinalam Marcondes et al. (2003), "seu trabalho e sua identidade como trabalhadoras continuam a ser de mulheres que, de certa forma, "não deveriam estar ali"' (p. 93). Do mesmo modo, apesar da ideia de que os homens de hoje participam, tanto quanto as mulheres, dos cuidados da casa e da família ter sido incorporada aos discursos atuais, na prática, ainda se pode perceber uma grande desigualdade entre homens e mulheres no desempenho dessas funções (Rocha-Coutinho, 2003; Teykal \& RochaCoutinho, 2007).

Segundo Negreiros e Féres-Carneiro (2005), estudos sobre temas os mais variados, realizados com segmentos médios urbanos brasileiros nas últimas décadas, apontam para a coexistência, no interior dos integrantes desses grupos, de padrões tradicionais e contemporâneos, opondo-se à ideia de que os novos modelos tenham substituído os antigos. Assim, a ordem, a certeza e as antigas classificações que vigoravam na modernidade parecem ainda persistir, resistir e coexistir com a dúvida, as mudanças e a transitoriedade que se pode observar na contemporaneidade.

Ou seja, no cotidiano, a identidade da mulher contemporânea com uma carreira profissional, como assinalam Negreiros e Féres-Carneiro (2005), continua a abarcar a identidade da mãe, sensível e cuidadora, que promove a segurança e o equilíbrio da família. Também Rocha-Coutinho (2003), em estudos sobre a identidade das mulheres brasileiras de classe média, observou, nos discursos de suas entrevistadas, uma oscilação entre o modelo de mulher tradicional, que valoriza a família acima de tudo, e o modelo atual, que prega a independência feminina e o investimento em uma carreira profissional. Desse modo, apesar de se valorizar hoje a realização feminina no espaço público, a identidade das mulheres atuais remete tanto aos padrões chamados "novos" como aos antigos.

Essas contradições, no que se refere às identidades, estão inseridas em um contexto maior de mudanças na sociedade, como assinalamos antes, em que as identidades culturais na contemporaneidade perderam suas antigas referências, o mesmo ocorrendo com as identidades pessoais. Segundo Hall (1997), os indivíduos encontram-se hoje fragmentados, o que, segundo ele, contribuiria, para a chamada crise de identidade pela qual os indivíduos estão passando na contemporaneidade. Para esse autor, as identidades atuais são continuamente formadas e reformadas, ou transformadas, de acordo com os sistemas culturais nos quais as pessoas estão inseridas. Em suas palavras,

\footnotetext{
à medida em que os sistemas de significação e representação cultural se multiplicam, somos confrontados por uma multiplicidade desconcertante e cambiante de identidades possíveis, com cada uma das quais poderíamos nos identificar - ao menos temporariamente. (Hall, 1997, p. 14)
}

Essas múltiplas identidades dos indivíduos são, assim, muitas vezes, contraditórias, de modo que a antiga crença em uma identidade una, integrada e coerente parece não mais vigorar. Tais contradições se apresentam tanto para a própria pessoa, quanto para aqueles à sua volta. Desse modo, hoje, as identidades são sempre incompletas e estão em constante processo de transformação.

Tendo em vista as transformações que vêm ocorrendo nos papéis sociais desempenhados pelas mulheres, em especial as de classe média, nas últimas décadas a que nos referimos acima $\mathrm{e}$, atentas às transformações ocorridas na FAB nos últimos anos, resolvemos desenvolver um estudo com o objetivo de melhor entender como se desenrola o processo de construção da identidade de mulheres oficiais do quadro de aviadores da Aeronáutica, que se formaram na primeira turma de aviadores da Academia da Força Aérea (AFA) em que foi permitido o ingresso feminino. Neste buscamos compreender como essas mulheres estão vivenciando a experiência de se inserir em uma carreira 
profissional, e, mais do que isso, como elas se sentem entrando em um universo tradicionalmente masculino e que, até pouco tempo atrás, era explicitamente proibido para elas.

Entre as questões que serviram de base para nosso estudo, estão: se as mulheres esperam constituir ou não uma família e, em caso positivo, como esperam conciliá-la com a profissão -; se enfrentaram ou vêm enfrentando algum tipo de pressão, discriminação ou dificuldades; e quais as maiores recompensas obtidas e/ou que esperam obter com relação à carreira que escolheram. No caso mais específico da profissão escolhida, outras perguntas aqui se levantam. Será que, na opinião das entrevistadas, as transformações ocorridas na instituição - que agora admite mulheres na aviação - são transformações já enraizadas, ou seja, que ocorreram também no plano das pessoas que nela trabalham? Sendo a mulher historicamente dominada pelo homem, como se estabelecem as relações de poder entre homens e mulheres na FAB, considerando que as instituições militares são instituições tradicionais fundadas nos pilares da hierarquia e da disciplina?

\section{Método}

Foram entrevistadas seis das onze ${ }^{4}$ mulheres aviadoras da turma de 2003, formadas em dezembro de 2006, com idades entre 22 e 25 anos. Todas fazem parte da primeira turma em que foi permitida a entrada de mulheres no quadro de aviadores na AFA. As participantes da pesquisa foram escolhidas pelo fato de que vão atuar em uma área que, na $\mathrm{FAB}$, até o momento de seu ingresso, era considerada a mais tradicionalmente masculina. Elas são, portanto, pioneiras nesse ambiente militar, ainda se adaptando a esta nova situação, o que, acreditamos, pode ser captado em seu discurso.

Cabe acrescentar aqui, ainda, que as mulheres que participaram do estudo encontravam-se, no momento das entrevistas, realizando cursos, na base de Natal, como oficiais estagiárias nos esquadrões por elas escolhidos. Isso porque, ao saírem da AFA, após os quatro anos do Curso de Formação de Oficiais Aviadores (CFOAV), os alunos escolhem (e são designados ou não - dependendo de sua classificação final no Curso da AFA e da indicação do instrutor) a aviação de caça, de helicóptero ou de transporte aéreo. Passam o ano seguinte concentrados em um dos três esquadrões responsáveis pelas instruções de voo.

Fizemos uso de entrevistas semidirigidas que tiveram uma estrutura invisível; isto é, apesar de partirem de um roteiro previamente elaborado, seguiam o fluxo da conversa. Quando um tópico não era abordado espontaneamente pela entrevistada, eram formuladas perguntas relacionadas a esse. O objetivo, nessas entrevistas, era que a entrevistada falasse o máximo possível, uma vez que quanto mais elas discorressem sobre os tópicos, mais rica poderia vir a ser a análise.

Todas as mulheres ${ }^{5}$ foram entrevistadas separadamente, em local e horário por elas escolhido. As entrevistas foram gravadas em áudio e transcritas na íntegra, e os textos daí resultantes foram submetidos a uma análise de discurso (Pinto, 1999; Rocha-Coutinho, 1998) a partir das seguintes categorias: Ser Mulher; Escolha Profissional, Questões e Dificuldades na
Carreira; e Aspirações na Esfera Profissional e Familiar. Cabe considerar que, apesar do caráter singular das falas de cada entrevistada, buscamos encontrar os temas comuns e os pontos em que os discursos convergiam ou divergiam, para desenvolver nossa análise.

\section{Análise dos resultados}

Nossa análise apontou para o fato de que, para as aviadoras entrevistadas, embora alguns aspectos acerca do que é ser mulher tenham mudado na sociedade atual, outros ainda estão em processo de mudança. De qualquer modo, todas as entrevistadas consideram essas mudanças positivas e acreditam que esse processo deve continuar ocorrendo:

\section{Ah, eu acho que foi uma conquista (...). Já faz um tempo que a mulher já tá entrando no mercado de trabalho; então, pratica- mente, agora existe uma igualdade, eu acho. Ainda tem algumas diferenças, né? Que não é a mesma quantidade de mulheres e de homens, mas, assim, tá evoluindo bastante [risos]. (Ângela)}

De modo geral, as aviadoras apontaram para o fato de que a mulher está se inserindo cada vez mais no mercado de trabalho e que já não se pode falar em funções exclusivas de homens ou mulheres:

as mulheres estão cada vez mais estudando, tão conseguindo ganhar um espaço grande no mercado de trabalho e tão se saindo bem nas profissões tão até conseguindo entrar em meios que eram praticamente masculinos, num tem mais limite "ah, essas aqui são mais de homem, essas mais de mulher”. (Sara)

Apesar disso, a maioria das entrevistadas acredita que algumas atividades são mais adequadas para os homens e outras para as mulheres. Ao explicar porque veem dessa forma, elas mencionam algumas características que seriam, supostamente, mais femininas ou masculinas e estariam, assim, mais de acordo com o que é requerido para o exercício de determinadas funções:

têm características que você vai ver mais em homens, mas num impede que uma mulher tenha essa característica e desempenhe. Por exemplo, babá é uma coisa de mulher, você imagina que a mulher vai ter mais cuidado com o bebê, com o cuidar de criança, cuidar de casa, mas pode ser que tenha homem que tenha todo esse cuidado assim e seja uma maravilha. De homem (...) a gente sempre tem aquele estereótipo, né? Pedreiro, (...) uma coisa bruta, trabalho forte, mas pode ter uma mulher que goste de fazer aquilo tudo, (...) saiba fazer bem e faça melhor. (Rita)

Pudemos observar na fala acima que, apesar do discurso inicial das entrevistadas apontar para uma igualdade entre os sexos, ainda permanecem, mesmo que de forma velada, alguns traços da antiga ideia da existência de características "essencialmente" femininas e masculinas, que explicariam a separação das esferas de atuação de homens e mulheres.

Ao se referirem à sua experiência profissional, talvez porque nossas entrevistadas tenham acabado de se formar, elas restringiram sua fala ao que haviam passado ao longo do curso na AFA e ao que estavam passando durante os cursos que estavam realizando nos esquadrões, isto é, às suas vivências 
e experiências atuais e aos obstáculos que estão tendo que ultrapassar:

me sinto orgulhosa de mim mesmo por ter conseguido passar tantos obstáculos na Academia e me formar (...) eu tô bem satisfeita com o desempenho das meninas é um desafio, né? (...) Eu cheguei lá, tive um choque, num tava acostumada (...) num sabia (...) como é que era o treinamento (...) fiquei meio perdida, mas depois eu comecei a pegar o ritmo. (Sara)

Ao serem questionadas sobre as características que consideravam necessárias para sua profissão, metade das entrevistadas ressaltou a determinação. Neste tópico, outras características como disciplina, responsabilidade, perfeccionismo e paciência também foram citadas: "Acho que tem que ter determinação, dedicação" (Ângela); "É determinação e disciplina" (Vera); "O curso exige uma certa responsabilidade e acho que isso aí tem a ver, dedicação também, eu gosto de, eu gosto, eu gosto de um desafio" (Bárbara).

Com relação às características que acreditavam possuir e que consideravam negativas e/ou positivas para seu desempenho profissional, as respostas foram diversas. Dentre as características negativas por elas apontadas, podemos destacar aqui o nervosismo, a ansiedade, a insegurança e o fato de serem mais emocionais e menos frias que os homens. Dentre as características positivas, elas mencionaram o fato de as mulheres serem, por natureza, mais caprichosas, cuidadosas e, principalmente, mais detalhistas, algo que, segundo elas, ajuda muito na profissão escolhida: “(...) você tem que deixar um pouco o lado emocional pra lá (...) Tem que começar a raciocinar, a pensar nas coisas um pouco mais friamente (...) a gente tem que raciocinar mais friamente" (Sara); "Acho que mulher é mais detalhista (...) acaba se apegando mais aos detalhes e isso é bom. Porque o voo em si é cheio de detalhes, entendeu?" (Ângela); “ (...) algumas fases do voo (...) um certo capricho a mais, um cuidado ali, faz a diferença. Isso aí eu acho que pelo instinto feminino pode trazer algum benefício" (Catarina).

Foi possível observar também que, de maneira geral, as aviadoras estão satisfeitas com a profissão escolhida ("Ah, é legal. Não é eu acho, (...) eu acho muito (...) legal”, afirmou Vera). Ao falar da felicidade que experimentam hoje por terem feito parte dessa turma, mencionaram por diversas vezes as dificuldades enfrentadas, os obstáculos que tiveram que ultrapassar e o trabalho empreendido para terem êxito no curso:

É uma situação (...) muito gratificante; assim, a gente vê que a gente tá fazendo parte de (...) um acontecimento na história da evolução da mulher e é gratificante pra caramba. Eu me sinto muito feliz, muito honrada (...) é o que dá força cada dia que a gente precisa passar por um obstáculo, porque a rotina aqui não é fácil, a gente rala bastante, (...) normalmente é disso aí que eu procuro tirar o meu ânimo. (Catarina)

Apesar de três das seis entrevistadas terem encontrado resistência por parte de familiares quando decidiram fazer o curso, todas afirmaram que atualmente têm o apoio de familiares e amigos, que se mostram interessados em sua profissão e ficam orgulhosos com suas conquistas: minha família me apoiou muito, meu pai ficou meio com medo, porque ele falou que aviação era uma coisa que ele nunca escolheria e eu acabei escolhendo ele ficou orgulhoso, mas meio receoso assim no início. Hoje, ele adora, né? A minha família toda, todo mundo fica babando. Meus amigos também gostam. (Sara)

Em seus relatos, as participantes mencionaram ter enfrentado algumas dificuldades durante o curso realizado na AFA. Dentre elas, o fato de terem ficado em evidência principalmente por terem feito parte da primeira turma de oficiais aviadoras mulheres -, as mudanças ocorridas em suas vidas em decorrência da profissão que decidiram seguir e a pressão constante a que estavam submetidas pela possibilidade de serem desligadas do curso, a qualquer momento, em decorrência de um desempenho ruim.

As entrevistadas afirmaram que o treinamento que recebem é igual àquele que é dado aos homens e consideram que o desempenho das mulheres é semelhante ao deles:

acho que é o mesmo nível de exigência porque a gente tá trabalhando com aviação; por que se exigir menos da mulher, pô? De repente, ali ela pode quebrar um trem e colocar a vida de várias pessoas em risco, entendeu? Ah, eu acho que a gente teve as mesmas dificuldades que os garotos, entendeu? (Vera)

Elas mencionaram, ainda, que são bem tratadas pelos superiores, mas divergiram com relação ao tratamento dado a elas pelos subordinados. Para algumas delas, apesar dos subordinados tratarem homens e mulheres da mesma forma, algumas mulheres são, por vezes, mais duras que os homens, tentam se impor mais, porque precisam mostrar que mandam:

tratam do mesmo jeito (...) Só que aí acaba acontecendo, eu não faço isso que, pô, eu me considero tranquila, entendeu? (...) Mas eu já vi assim acontecer de como (...) ela é mulher, então ela num vai ter pulso firme, entendeu? E o cara vai poder, ela acha que o subordinado vai fazer o que ele quiser, (...) então ela tende a cobrar mais (...) ela tende a acabar sendo mais rígida. (Bárbara)

Uma das entrevistadas mencionou até mesmo um pedido feito por um subordinado que credita ao fato de ele achar que, por ela ser mulher, seria mais boazinha, teria o coração mais mole:

(...) geralmente, serviço de mulher, eles acham que podem alguma coisa, (...) que (...) a gente vai ser mais frágil, mais boazinha de coração. (...) Teve um cara que veio chegar pra mim porque ele ia tirar a carteira de motorista (...), que ia embora $6: 30 \mathrm{~h}$, 7:00h da manhã. Eu falei assim "não, só vai embora quando passar o serviço, eu só vou embora quando passar o serviço e você também" (...) se fosse um amigo meu, infante, (...) fosse um homem, um galalau, ele num ia falar nada porque ia ter medo de chegar pra o homem e contar historinha triste. (Rita)

Todas, contudo, acreditam que, também depois de formadas, o nível de exigência é igual para mulheres e homens; a maioria vê o tratamento que recebem no trabalho agora como sendo igual ao que é dado aos homens, ainda que algumas tenham afirmado que os superiores são mais educados, formais e tratam as mulheres com mais cordialidade, enquanto que, no trato com os homens, 
há maior camaradagem:

Entre os homens eu acho que rola mais camaradagem (...). Com a gente é mais formalidade (...). No mesmo voo de navegação (...), um instrutor com o outro fica contando piada, conversando; com a gente, eles ficam normais, falam sobre as coisas normais, ou não falam. Eu acho que existe uma (...) questão de educação maior. (Vera)

As entrevistadas fizeram, contudo, ressalvas em relação ao momento inicial de convivência na Academia, em que acreditam ter recebido tratamento diferenciado, o que é atribuído ao fato de sua entrada ter constituído uma situação nova para todos. Apesar disso, não consideram que essa diferença tenha sido provocada por preconceito, discriminação ou ocorresse de maneira pejorativa. Assim, apesar da igualdade de tratamento e nível de exigência, afirmaram ter recebido mais atenção que os homens:

O curso é a mesma coisa e tem que ser a mesma coisa porque, afinal de contas, a gente vai voar o mesmo avião, nas mesmas situações, então, eu tenho que ter o mesmo controle que um cara da minha turma vai ter (...). Só que eu acho que, por ser mulher, e serem poucas e também por ser a primeira turma e ser novidade (...) eles acabam dando mais atenção pra gente (...), eles acabam acompanhando a gente de muito mais perto do que acompanham os garotos. (Bárbara)

Foi possível notar que, de certa maneira, durante as entrevistas, as participantes se referiram mais às questões ligadas à instrução e ao treinamento. Mesmo quando a pergunta não estava direcionada a isso, mencionavam exemplos de sua experiência nessas áreas. Talvez essa tendência possa ser explicada pelo fato de que, até o momento da entrevista, as participantes não tenham tido muito contato com outras atividades da FAB, que não aquelas relacionadas à sua aprendizagem e preparação. Vale lembrar que, mesmo fora da AFA, ainda permaneciam em instrução para especialização em algum tipo de aviação, nos esquadrões específicos.

Cabe destacar, também, que os homens constituem o parâmetro utilizado por elas para se referir a tudo o que fazem. Falas como "é necessário fazer o que os homens fazem", comuns nos discursos das entrevistadas, talvez resultem do fato de estarem sendo as primeiras mulheres em uma carreira até então destinada somente a homens. Assim, já se sabe que os homens são capazes de realizar as tarefas requeridas, enquanto as mulheres ainda precisam provar que também conseguem realizálas. Contudo, ressalta-se que as próprias perguntas feitas nas entrevistas suscitaram, em muitos momentos, essa comparação entre homens e mulheres. De qualquer modo, para todas as entrevistadas, o desempenho nos treinamentos independeu do sexo, ainda que os instrutores estivessem um pouco receosos no início:

Nenhum problema que se possa dizer assim "ela num conseguiu fazer porque é mulher" (...). Pode ter tido mais dificuldade, assim como alguns homens tiveram (...), acho que (...) nada que se possa dizer que o fato de ser mulher tenha atrapalhado. (Catarina)
Eles [instrutores] tavam, no início, com receio. Ninguém sabia como ia ser nosso comportamento no voo, se a gente ia conseguir atingir os parâmetros (...). Só que não teve esse problema. (Ângela)

Apesar de as entrevistadas terem dado muita importância à profissão, quando perguntadas sobre suas expectativas de vida e perspectivas para o futuro, demonstraram também o desejo de constituir uma família e serem mães, ainda que acreditem que a maternidade deverá ser planejada e não é algo que esteja em seus planos para o futuro próximo: “Ah, com certeza [quero ter filhos]! Num sei ainda quando (...); planejo, sei lá, daqui a uns seis anos, sete, por aí. Se eu puder planejar, né? Vai ser por aí" (Catarina); "Num sei por que, eu acho que toda mulher sonha com isso. É difícil você ver alguém que não sonha com isso, né? Eu sonho. Mas é bem pro futuro [risos]" (Sara).

Embora queiram ser mães, todas - com exceção de uma das entrevistadas - acreditam que terão grande dificuldade para conciliar carreira e maternidade devido à profissão que exercem. Os motivos mencionados foram os mais diversos, variando de viagens e mudanças frequentes de cidade, e até mesmo de estado, à recuperação do condicionamento físico - tão importante para sua profissão - após o parto:

Eu vejo por falta de tempo, porque às vezes tem (...) que sair do lugar onde a gente trabalha, tem que viajar. Eu pretendo ir pra um lugar que não voe muito quando eu quiser ter filho porque aí eu faço o voo que dá. (Sara)

Se eu quiser dar minha ênfase pra carreira eu tenho que ser transferida daqui a cinco anos. Então eu vou ficar pingando de lugar em lugar a vida inteira (...) e isso é um problema. (Rita)

(...) o voo desgasta muito, então eu acho que talvez a gente demore mais um pouco pra se recuperar e voltar $100 \%$ pro trabalho depois de uma gravidez (...), pra garantir que eu vou voar e não vai acontecer nada. (Catarina)

Metade das participantes afirmou já ter tido problemas de relacionamento afetivo devido à profissão escolhida. Em todos os casos, isso se deu devido à distância física entre elas e os namorados:

Ah, terminei com meu namorado (...) por causa da distância. Acho que isso me atrapalhou (...) é mais difícil, é um pouco mais difícil (...). Eu acho que os homens se assustam (...) acho que a grande saída é namorar militar, entendeu? (Vera)

As outras entrevistadas disseram não haver problemas afetivos, atribuindo isso ao fato de estar namorando ou só ter se relacionado com homens da FAB, ou com outros militares:

(...) por enquanto não, porque meu namorado também é da mesma carreira (...). Mas (...) acredito que seja um pouco difícil (...) pra mulher (...) pilotos se envolverem com caras que não são do metié, (...). Vai ser difícil o homem entender, porque (...) por ser militar tem que mudar (...) de tanto em tanto tempo (...). Acho muito difícil pra um civil ficar acompanhando a esposa (...) acho que é impossível. Me resignei já, que vai ser um militar e acabou, mas, em outros casos pode ser que 
consigam, né? (Bárbara)

Cabe observar aqui que, segundo as entrevistadas, os homens não têm a mesma dificuldade, o que pode apontar para o fato de que parece prevalecer a ideia, bastante difundida no discurso social, de que, enquanto a profissão é algo fundamental na vida de um homem - ainda que muitas mulheres agora também invistam em uma carreira profissional -, para as mulheres, o casamento e a família ainda têm um peso bastante grande - impondo limites às suas escolhas profissionais e aos relacionamentos afetivos -, mesmo quando afirmam que a carreira escolhida - como é o caso das mulheres aviadoras que entrevistamos - tem uma importância fundamental em suas vidas. Assim, apesar da sociedade e das próprias mulheres e homens continuarem a achar "natural" que uma mulher abandone tudo, inclusive a carreira profissional, para seguir seu marido, o mesmo parece não se verificar no caso dos homens.

\section{Considerações finais}

Nosso objetivo nesse trabalho foi melhor entender mulheres brasileiras que, não apenas estão se inserindo em uma atividade profissional, mas, mais do que isso, penetraram em um universo tradicionalmente masculino - o de oficiais pilotos da Aeronáutica -, que havia acabado de se abrir para elas. Ao longo do trabalho, pudemos observar um pouco melhor suas vivências, problemas, dificuldades e aspirações, e constatar que estas aviadoras militarem fizeram importantes conquistas na esfera pública, abrindo e conquistando espaço e respeito em um ambiente, até pouco tempo atrás, impensável para as mulheres.

Embora ainda estejamos vivendo um momento de mudanças aceleradas no que diz respeito à participação feminina no mercado de trabalho, foi possível identificar no discurso de nossas entrevistadas uma transformação nos valores sociais relacionados à posição ocupada pelas mulheres. Mesmo que ainda seja esperado e cobrado das mulheres que desempenhem funções tradicionalmente associadas a elas no interior do lar, o discurso social hoje parece apregoar sua satisfação e a realização pessoal, incentivando e permitindo, desta maneira, que elas busquem outras formas de viver e se realizar plenamente, que não apenas na dependência e à sombra de seus maridos. Isso pode ser visto, por exemplo, no apoio dado a essas mulheres aviadoras por seus familiares e amigos.

Os dados resultantes da análise das entrevistas por nós realizadas se mostraram coerentes com o que tem sido apontando por pesquisas realizadas sobre as mudanças por que vêm passando as mulheres atuais (Araújo \& Scalon, 2005; Negreiros \& Feres-Carneiro, 2005; Rocha-Coutinho, 2003; Teykal \& Rocha-Coutinho, 2007; Vieira, 2005). Identificamos, assim, que as mulheres entrevistadas acreditam se encontrar hoje em melhor condição na sociedade, no que diz respeito ao papel e à posição que ocupam e ao que delas é esperado e exigido, apesar de entenderem que as mudanças ainda são lentas e que este processo ainda está em curso.

Contudo, foi possível perceber também a permanência, em seus discursos, de padrões masculinos no ambiente de trabalho das mulheres aviadoras militares entrevistadas. Isto é, parece que ainda continua a ser necessário que as mulheres se adaptem e ajam no trabalho em conformidade com os comportamentos tradicionalmente estabelecidos pelos e para os homens. Desta forma, apesar de as mulheres não serem excluídas de maneira clara e explícita da carreira que escolheram, poderíamos pensar em um tipo de exclusão velada, já que é possível supor que a necessidade de tal adaptação, de certo modo, além de dificultar a atuação feminina, pode restringir o interesse pela carreira por parte de algumas mulheres.

A divisão sexual de trabalho, que atribui diferentes tarefas a homens e mulheres, parece continuar a ser reforçada por nossas entrevistadas. Mesmo negando a existência de funções exclusivamente masculinas e femininas, elas afirmaram, ao longo das entrevistas, que algumas funções seriam mais apropriadas para homens e outras para mulheres, atribuindo-lhes características ligadas a traços que continuam a ser considerados inerentes ao sexo das pessoas. Da mesma forma, na opinião das entrevistadas, as dificuldades associadas a um possível casamento e maternidade/paternidade continuam a pesar mais sobre as mulheres que sobre os homens, já que essas ainda parecem acreditar que a mulher é a principal responsável pela casa e pelos filhos.

Assim, podemos dizer que a identidade das mulheres aviadoras da FAB se constrói tanto a partir de padrões tradicionais, que valorizam a maternidade, a família e o espaço da casa, quanto de padrões contemporâneos, que preconizam a independência financeira e o investimento em uma carreira profissional, mesmo tendo optado, de forma pioneira, por uma carreira até então aberta apenas aos homens. As aviadoras entrevistadas sentem-se felizes, contudo, por fazerem parte da primeira turma de aviadores em que foi permitido o acesso de mulheres e veem o sucesso profissional como um de seus grandes objetivos para o futuro, pelo menos imediato.

Entretanto, pode-se notar também em seus discursos a permanência de ideais e visões tradicionais, já que, apesar do desejo de constituir família e de ser mãe ser comum a todas as entrevistadas, mesmo que ele tenha que ser adiado para um tempo futuro, diferentemente do que ocorre com seus colegas do sexo masculino, sua carreira impõe certas restrições à escolha de um companheiro, uma vez que são frequentemente transferidas de cidade e até mesmo de estado e, conforme assinalaram, praticamente apenas um companheiro militar poderia entender e acompanhá-las nessas mudanças.

Por fim, no que tange às relações de trabalho, parece que os princípios da hierarquia e da disciplina, fundamentais no ambiente militar, como aponta Castro (2004), interferem positivamente, tornando-as mais igualitárias entre homens e mulheres que exercem um mesmo posto. Desse modo, até mesmo os homens, quando subordinados às mulheres, devem respeitar as suas ordens pelo bem da hierarquia e da disciplina militar.

Apesar disso, a maioria das entrevistadas mencionou que os oficiais superiores fazem uso de um tratamento mais cordial e respeitoso quando se dirigem a elas do que a seus colegas do sexo masculino, quando predomina uma relação de maior camaradagem e intimidade. Essa diferença de tratamento, relatada pelas entrevistadas, é percebida como normal ou, no máximo, como algo esperado pelas próprias mulheres, que 
entendem que homens e mulheres são diferentes e, como tal, são naturalmente tratados de maneiras distintas na sociedade, quando interagem com pessoas do mesmo sexo ou do sexo distinto.

Esperamos que nosso estudo contribua não apenas para uma melhor compreensão de como as mulheres aviadoras da FAB estão vivenciando a experiência de inserir-se em uma carreira até então dominada por homens, como também para ampliar o conhecimento acerca da relação das mulheres com o trabalho na sociedade brasileira atual e da forma como a sociedade e elas próprias percebem a mulher trabalhadora. Tentamos estabelecer um quadro a partir da visão de mulheres sobre sua inserção numa carreira tradicionalmente masculina, mas acreditamos na importância da realização de outros estudos com grupos distintos de mulheres, a fim de que se possa ter uma visão mais ampla sobre os papéis e as posições de ambos os sexos nas relações familiares e de trabalho no Brasil atual. No momento, concordamos com pesquisadores da área (e.g., Araújo \& Scalon, 2005) que apontam para a ideia de que, apesar de novos padrões de comportamento já poderem ser sentidos em nosso país, eles continuam a coexistir com os modelos tradicionalmente estabelecidos para homens e mulheres.

\section{Referências}

Araújo, C., \& Scalon, C. (Orgs.). (2005). Gênero, familia e trabalho no Brasil. Rio de Janeiro: Fundação Getúlio Vargas.

Araújo, N. B., \& Yazbek, V. C. (2001). Ferramentas conversacionais: a práxis no construcionismo social. Cadernos do Familiae, 4(17), 25-31.

Bauman, Z. (1999). Modernidade e ambivalência. Rio de Janeiro: Jorge Zahar. Castro, C. (2004). O espírito militar: um antropólogo na caserna. Rio de Janeiro:
Zahar.

Giddens, A. (2002). Mundo em descontrole: o que a globalização está fazendo de nós (M. L. X. A. Borges, Trad.). Rio de Janeiro: Record.

Giddens, A. (2003). Modernidade e identidade (P. Dentzien, Trad.). Rio de Janeiro: Jorge Zahar.

Hall, S. (1997). A identidade cultural na pós-modernidade. Rio de Janeiro: DP\&A.

Marcondes, W. B., Rotenberg, L., Portela, L. F., \& Moreno, C. R. C. (2003). O peso do trabalho "leve" feminino à saúde. São Paulo em Perspectiva, 17(2), 91-101.

Moita Lopes, L. P. (2003). Socioconstrucionismo: discurso e identidade social. In L. P. Moita Lopes (Org.), Discursos de Identidades (pp. 13-38). Campinas: Mercado de Letras.

Negreiros, T. C. G. M., \& Féres-Carneiro, T. (2005). Masculino e feminino na família contemporânea. Estudos e Pesquisas em Psicologia, 4(1), 34-47.

Pinto, M. (1999). Comunicação e discurso: introdução à análise de discursos. São Paulo: Hackers.

Rocha-Coutinho, M. L. (1994). Tecendo por trás dos panos: a mulher brasileira nas relações familiares. Rio de Janeiro: Rocco.

Rocha-Coutinho, M. L. (1998). A análise do discurso em Psicologia: algumas questões, problemas e limites. In L. Souza, M. Freitas, \& M. Rodrigues (Orgs.), Psicologia: reflexões (im)pertinentes (pp. 317-345). São Paulo: Casa do Psicólogo.

Rocha-Coutinho, M. L. (2003). Quando o executivo é uma "dama": mulher, carreira e relações familiares. In T. Féres-Carneiro (Org.), Família e casal: arranjos e demandas contemporâneos (pp. 57-77). Rio de Janeiro: Editora da PUC-Rio; São Paulo: Loyola.

Teykal, C., \& Rocha-Coutinho, M. L. (2007). O homem atual e a inserção da mulher no mercado de trabalho. Psico, 38(3), 262-268.

Venturi, G., Recamán, M., \& Oliveira, S. (Orgs.). (2004). A mulher brasileira nos espaços público e privado. São Paulo: Fundação Perseu Abramo.

Vieira, J. A. (2005). A identidade da mulher na modernidade. Delta, 21(especial), 207-238. 
1. Pode-se dizer que o termo gênero é empregado para distinguir o sexo, biologicamente determinado, dos significados sociais a ele relacionados.

2. Estamos considerando aqui "profissões de mulher" aquelas profissões que envolvem traços ou características tradicionalmente associados às mulheres, como é o caso das enfermeiras e professoras primárias, que envolvem o cuidado com o outro e a educação de crianças, respectivamente.

3. O quadro de intendentes nas Forças Armadas envolve os oficiais formados pela AFA que se dedicam a funções administrativas.

4. Cabe assinalar aqui que a turma tinha inicialmente vinte mulheres matriculadas, das quais apenas onze se formaram aviadoras. As outras nove mulheres que ingressaram no curso foram desligadas ou se desligaram do curso de aviação ao longo dos quatro anos. É importante acrescentar que é comum que parte dos alunos, mesmo do sexo masculino, sejam desligados ou abandonem o curso por livre iniciativa, muitos deles devido aos treinamentos físicos muito rigorosos. Foram entrevistadas apenas seis das onze aviadoras que concluíram o curso porque as outras cinco estavam indisponíveis durante o período em que estivemos em Natal para realizar as entrevistas. Das seis entrevistadas, parte delas estava estagiando em aviação de caça e parte em transporte aéreo. Infelizmente, nenhuma das estagiárias de helicóptero estava disponível na ocasião.

5. Os nomes empregados para nos referirmos às mulheres entrevistadas são fictícios.

Marina Miranda Lery Santos, mestre em Psicossociologia de Comunidades e Ecologia Social pela Universidade Federal do Rio de Janeiro, é psicóloga do Comando da Aeronáutica em Brasília-DF. Endereço para correspondência: SQN 202 bl.B/501, Brasília-DF. CEP: 70832-020. Telefone: (61)8176-7509. E-mail: marinasnts@yahoo.com

Maria Lúcia Rocha-Coutinho, doutora em Psicologia pela Pontifícia Universidade Católica do Rio de Janeiro, é professora colaboradora do Programa EICOS na Universidade Federal do Rio de Janeiro e professora titular do Curso de Pós-Graduação em Psicologia da Universidade Salgado de Oliveira-RJ. Endereço para correspondência: Rua Engenheiro Cortes Sigaud, 187 apt. 401, Leblon, Rio de Janeiro-RJ. CEP: 22450-150.

Tel.: (21) 2294-9452. 